Subject Entry Section, Title Index and Author Index. The most useful and distinctive features of this Bibliography of Bioethics are its Bioethics Thesaurus and analytical Subject Entry Section, which allow for most detailed cross-referencing and systematic study of related or over-lapping areas, terms or concepts. The range of subject headings covered is enormous. In addition to the familiar topics of euthanasia, abortion, psychosurgery, human experimentation and the definition of death, it also covers a vast range of less familiar issues - including issues of an ethical, social, political, religious, legal as well as of a specifically medical character.

This points to a difficulty in the use of the term Bioethics - it can cover almost anything. In the introduction to the Bibliography of Bioethics, LeRoy Walters defines bioethics as 'the systematic study of value questions which arise in the biomedical and behavioural fields'. $\mathrm{He}$ goes on to explain that this covers health-care ethics, research ethics and the development of reasonable public-policy guidelines. The use of the term 'medical ethics' in the rest of the English-speaking world is not just a matter of oldfashioned linguistic prejudice and allergy to the almost prescriptive use of neologisms like 'bioethics' and 'ethicist' in American literature, but also represents an attempt to limit the scope of the subject. Nevertheless it is a remarkable achievement to classify and present in such a useful form a bibliography of literature in this rather diffuse multi-disciplinary field - where there is little agreement about appropriate methods of research or investigation.

The bioethics thesaurus is a most useful instrument for finding one's way about the field. A typical entry on abortion gives the following crossreferences: abortion laws, compulsory abortion, mandatory abortion, abortion on demand, illegal abortion, selective abortion, therapeutic abortion and aborted fetuses. Under each of these headings in the subject entry section there are listed relevant articles and books. (The entry in the thesaurus on AID donors helpfully says: Use semen donors!) Current interest in death is reflected in no less than $4 \mathrm{I}$ cross-references given under the main headings of allowing to die, death, euthanasia, prolongation of life, terminal illness and terminal care, and the list of authors cited is a veritable Who's Who of thanatologists. The thesaurus and indexes provide invaluable aids to detailed scholarship in the new and interesting field. Whether besides the compilers and familiar contributors there are enough specialists to make full use of so exhaustive and compendious a bibliography is another matter, but doubtless future generations will be grateful for this record of the literature of the sixties and seventies.

The Bibliography of Bioethics, like the Bibliography of Society, Ethics and the Life Sciences, purports to be comprehensive. Nevertheless it is characteristically American, both in its selection of topics and bias towards American material. Coverage of American journals is much more exhaustive than journals from other english-speaking countries and does not take account of the increasing number of articles in English appearing in European and Asian periodicals. Unfortunately its cost is prohibitively American as well, and unlike the Hastings Center Bibliography, the Bibliography of Bioethics will probably be available only in libraries at those few centres that seek to promote the study of medical ethics. With their generous and clear lay-out, admirable bibliographical tools, quality printing and expensive binding the available 5 volumes were probably designed for sale to libraries anyway. Nevertheless, wealthy doctors and the odd 'ethicist' who can afford 220 dollars for the set will find them an invaluable aid and veritable mine of information.

IAN E THOMPSON

Rethinking Community Medicine: towards a renaissance in public health.

A report from a study group. Unit for the Study of Health Policy, 8 Newcomen Street, London SEI IYR, 1979

The Medical Role in Environmental Health

H A Waldron, Nuffield Provincial Hospitals Trust, Oxford University Press. 1978

Rockefeller Medicine Men: medicine and capitalism in America

E Richard Brown, University of California Press, Berkeley, Los Angeles. 1979

Pain, felt by individuals may be caused by society which has a moral duty to prevent ill-health where it can and care and cure where prevention has failed. We, in this country, recognised this when at last we set up a comprehensive health service in 1948. Care and cure aspects of the service were at once more strongly developed and better supported than prevention because the social nature of medicine was improperly understood. That medicine is a social science practised by the community and its representatives is a lesson that still has to be learned above all by the medical profession. Books such as these will be the means of instruction of both the profession and the public.

Rethinking Community Medicine is full of good ideas and suggestions. However, through the inevitable compression of a large subject in a small book, it lacks argument in the last two chapters and, as the final paragraph seems to admit, it becomes peremptory and dogmatic. It claims too much for health professionals.

It is true that health affects everything and everything affects health, but to suggest, as the Study Group does, that unemployment and road transport should be investigated as causes of ill-health, in the latter case by a special 'Health Promotion team' is carrying professional interests too far. Health has always been and continues to be a by-product of increasing amenity. The sanitary revolution of the Igth century did not wait until the germ theory of disease could prove that cleaning up streets, shops and dwellings would reduce infectious disease. People improve their diet, their housing, seek employment, not with the idea that they will thereby be healthier and live longer but to feel more comfortable now. Much of what the Study Group discusses are matters for citizens' concern as political beings to be struggled for through such democratic organisations as political parties, trades unions and churches and not by the creation of what are essentially undemocratic organisations - bodies of professional people working for a local or central government, whose knowledge is not available to the public or the press. What is most needed is freedom of information to enable us to discover the mass of knowledge that already exists, in the files of the police, for example about dangerous makes of cars, of the fire service, for example 
about dangerous furnishing materials and other fire hazards, of the Health and Safety executive about dangerous factories and industrial processes, of the environmental health departments of local authorities about dirty and dangerous cafés, butchers and other food shops. The British Official Secrets Act and libel laws, in respect of health, and probably other things, protect the negligent and the wicked and put in danger the mass of innocent citizens. There is no reason to suppose that 'National Health Promotion Teams' could serve us any better.

The Medical Role in Environmental Health is a little book that performs the difficult task of describing the interlocking relations of the dozens of government departments, quangos and local authorities, private and nationalised industries and the health service, all monitoring the environment in the interests of our health. The Medical Officer for Environmental Health has a difficult job. He must advise his health board and assist his local authorities with inadequate resources and information. To remedy this, Waldron also proposes a team. His is to be made up of representatives of public organisations with overlapping interests. However, once more the laws ensuring secrecy would hinder free communication within the team and prevent the public information necessary for a healthy political response to its findings.

This book is admirably suited to the needs of students. It is a pity it lacks an index and $£ 2.50$ for 64 pages is a bit steep even for these days.

Rockefeller Medicine Men develops the story of American medicine from the beginning of the century to the present day. It informs us about the role played by the huge charitable trusts associated with industrial fortunes and specially emphasises the Carnegie and Rockefeller Foundations. Their founders were amazingly frank about their purposes. They wished to preserve their fortunes, keep the control of their enterprises in the family, and through the charitable nature of the trusts encourage the belief in large numbers of American citizens that the most aggressive capitalists were basically simple people with hearts of gold. They set out to capture a major profession, medicine, and the universities that nourished it and win them for support of 'scientific' medicine and laboratory research and teaching. They converted medicine into a highly technological capitalist industrial enterprise supporting subsidiary industries in insurance and drugs and spending about one-eighth of the country's finances. But not content with control of medical education and practice they sought to determine the way American citizens think about their illnesses. Ill-health is individualised. You are ill because of some personal defect. You eat too much or drink too much or smoke too much. Treatment is to alter you, by exhortation to change habits, or by performing an operation or by prescribing a medicine. No one associated with the foundations suggests social change as a method of preventing disease.

This is a fascinating book. It tells an interesting story extremely well. It is, however, irritating to discover that either through poor editing and revision or because the author does not trust the reader's memory, that within a small number of pages, he repeats ideas, phrases, sentences and even a note with a quotation.

These books in their use of the term 'scientific medicine' adopt the common Anglo-Saxon habit of confusing science with technology. Scientific medicine does not mean to them an internally harmonious body of knowledge which can be used by society for the increased comfort and well-being of its citizens. They mean the use by teams and individuals, of physical, chemical and electronic gadgetry, some of it useful, much of unproven value, but all spectacular and impressive. The authors are all very well aware that medicine is a social science with social and political solutions that determine the value and outcome of the merely technological approaches to health problems.

DONALD CAMERON

\section{A physician faces cancer in himself}

Samuel Sanes, State University of New York Press, 1979, 201pp.

The English tend to have, of course, a fantasy picture of the typical American: generous, brave, unoriginal, naive, yet shrewd. And there may be as much truth in that as in the transatlantic vision of the Englishman as unsure, nostalgic, intelligent, work-shy, envious, lacking in conviction and self-respect.

These not very original thoughts surface many times on reading this little book. It begins by the effertless production of platitudes 28 if they were thundering new truths. To English ears the foreword bythe wife is almost a send-up of the b $b \mathrm{k}$,

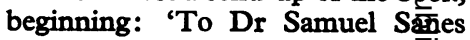
all of life was a learning experiersze'. The doctor then hammers it $\mathbb{\Phi}$ all home by such telling phrases as 'fife has a way of setting a man back on his heels'. Thus it is a book mostly written in graceless journalese; a book whose banality of thought $\overrightarrow{\text { and }}$ expression render second-hand ind predictable the last months of a worthy physician whose progresg is recorded from the diagnosis $\rightarrow$ of malignant lymphoma to his corrieting proofs two weeks before deatio.

This is the truth: but it is notghe whole truth. The journalese style, is at least better than the tortuejs tedium of much academic writifg: and the banality becomes in a strafge way valuable and absorbing touching as we see a man accepted unquestioningly the values of medicine and of life in a way typical of his society, but who describes his courage without integding to, and the difficulties of colleagues and friends because he So $_{\mathrm{S}}$ fully shared them.

The book then becomes less a chronicle of a single man than an uncut piece of social history. The trite faith is there: 'The family should be impressed by the fact that the threat of cancer never ends, even with a supporting "cure", and that it is good insurance to have perio checkups.' But keeping it company is the honest recognition of inadequacy 'Hopelessness and helplessness may disorganise family life. They can send patients and families to other physicians or even lead them to consult quacks or to use scientifically usimproven methods at a time when cancers may still be in controlla $\bar{b}$ e form'.

Gradually as I read this book impatience and condescension weope overwhelmed by respect for the author's honesty and courage. It was an emotional mixture that I had fit before, but it took some time gुo recognise it. Eventually I remembered - it was the way I had falt when I read my old father's warr diaries from the First World W Samuel Sanes' war diary also dẹcribes a big battle and a good main, and inevitable doom. No matter how it is told, that is a fine story. BRIC WILES 